\title{
Environmental Hydraulics
}

Edited by

J.H.W.Lee

The University of Hong Kong, China

A.W.Jayawardena

The University of Hong Kong, China

Z.Y.Wang

International Research and Training Centre on Erosion and Sedimentation (IRTCES), China

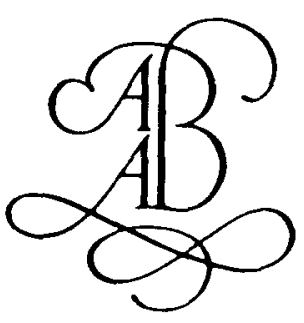

UNMERSITÄTSBIBLIOTHE:

HANNOVER

TECHNISCHE

WNFORMATIONSBIBLIOTHEK 


\section{Table of contents}

Editor's foreword

Organization

$1 \quad$ Hydrodynamic and water quality modelling

\subsection{Hydrodynamics and water quality of Hong Kong waters}

Keynote lecture: The CBS (Characteristic Based Split) algorithm in hydraulic and shallow water flow

O.C.Zienkiewicz \& P.Ortiz

Keynote lecture: Recent advances in computational hydraulics

T.J.Weare

3D water quality modelling of Deep Bay

T.A.Nauta, H.S.Lee, A.Kwok \& E.Gmitrowicz

3-dimensional water quality and hydrodynamic modelling in Hong Kong

I. Concepts and model set-up

A.K.M.Ng, A.Roelfzema \& L.J.M.Hulsen

3-dimensional water quality and hydrodynamic modelling in Hong Kong

II. Forcing residual currents

R.E.Uittenbogaard \& L.J.M.Hulsen

3-dimensional water quality and hydrodynamic modelling in Hong Kong

III. Stratification and water quality

L.Postma, G.S.Stelling \& J.Boon

\subsection{Numerical modelling}

Invited lecture: Strategy for coupling hydrodynamic and water quality models for addressing long time scale environmental impacts

A.F.Blumberg \& J.J.Fitzpatrick

Impact of a tide-overtopping barrage on water quality and subsequent management 
On the use of laboratory observations to validate number
D.L.Boyer, N.Pérenne, D.C.Smith \& C.Robichaud

Prediction of the behaviour of marine oil spills: Applications based on random walk techniques

Z.Li \& C.T.Mead

Modelling of sediment plumes caused by dredging operations

P.A.Mackinnon, Y.Chen \& G.Thompson

Three-dimensional mathematical modeling of pollutant transport in stratified estuaries

D.L.Young, B.C.Her \& Y.F.Wang

\subsection{Jets and plumes - I}

Invited lecture: The effects of wind stress on the spread of a buoyant surface layer

Numerical simulation on turbulent buoyant jets in a cross-flow of stratified fluids

R.R.Hwang \& T.P.Chiang

The axisymmetric jet in a coflow

S.J.Gaskin \& I.R.Wood

A semi-analytical self-similar solution of a bent over jet in crossflow

Li Lin, J.H.W.Lee \& V.Cheung

The spreading rate of a single coflowing axisymmetric jet

H.J.Wang \& M.J.Davidson

Momentum-based solutions for buoyant jet trajectories in still and flowing ambient fluids

K.L.Pun, M.J.Davidson \& I.R.Wood

Anisotropic buoyant turbulence model and its application

X.Zhou, Y.Chen, K.Yang \& Y.Li

Discharge and mixing of artificially upwelled deep ocean water

C.C.K.Liu \& H.Lin

Experiments on 2-D submerged vertical jets with progressive water surface waves

J.Kuang \& C.T.Hsu

Turbulence of a non-buoyant jet in a wave environment

M.Mossa

Laboratory measurements of a jet discharged into waves

C.Swan \& S.H.Kwan

Numerical simulations of a jet in a wave-induced oscillatory flow

S.H.Kwan \& C.Swan 
1.4 Jets and plumes - II

Radially spreading surface flow

M.MacLatchy \& G.Lawrence

Laboratory experiments on the impact of a buoyant jet with a solid boundary

A.Cavalletti \& P.A.Davies

Barge dumping of rubble in deep water

J.Bühler \& D.A. Papantoniou

Effects of boundary and buoyancy on jet behavior in cold water

R.Gu

A numerical study on the stability of a vertical plane buoyant jet in confined depth

C.P.Kuang \& J.H.W.Lee

Simultaneous velocity and concentration measurements of buoyant jet discharges with combined DPIV and PLIF

A.W.K.Law \& H.Wang

A study of plane wall jet for destroying density current

Z.Zhang \& W.Duan

The velocity field of a circular jet in a counterflow

C.H.C.Chan \& K.M.Lam

On the penetration of a round jet into a counterflow at different velocity ratios

C.H.C.Chan, S. Bernero \& K.M.Lam

\subsection{Outfall modelling}

Round plumes at plane surfaces

237

W.E.Frick

3-D numerical simulation on dilution behavior of near field for river diffuser

W.Huai, W.Li \& T.Komatsu

Evaluation of mixing zone models: CORMIX, PLUMES and OMZA with field data

from two Florida ocean outfalls

H.Huang, R.E.Fergen, J.J.Tsai \& J.R.Proni

Jet scouring of ambient sediment in the outfall of stage 2 Shanghai Sewerage Project

H.Wei, C.Liu \& J.H.W.Lee

Near field dilution study of bailong gang wastewater outfall of stage 2 Shanghai

Sewerage Project

H.Wei, G.Xu, J.H.W.Lee \& K.W.Choi

Application of thermal plume modelling and establishment of initial mixing zone

Y.Chen \& G.Thompson 
2 Transport and mixing processes

2.1 Turbulent shear flows

Keynote lecture: Turbulent transport and mixing in a stratified lake

J.Imberger

Invited lecture: Setting the stage: Large eddy simulation of laboratory scale flows

R.L.Street

Invited lecture: Large scale flow structures and mixing processes in shallow flows

G.H.Jirka

Mutual-interaction between bursts and boils very near the free-surface of open-channel flows

297

I.Nezu \& T.Nakayama

3-D turbulent structures in partly vegetated open-channel flows

305

I.Nezu \& K.Onitsuka

Coherent flows structures in unsteady open-channel flows over dune bed

A.Kadota, I.Nezu \& K.Suzuki

Coherent structures in unsteady open-channel flows

K.Onitsuka \& I.Nezu

Body-force effect of friction on quasi-two-dimensional turbulent flows in shallow waters

W.Altai \& V.H.Chu

Effects of vegetation on flow structures and bed profiles in curved open channels

A.Tominaga, M.Nagao \& I.Nezu

Experimental study of wakes behind submerged solid plate and porous plate

D.Chen \& C.C.Cheng

\subsection{Turbulent mixing in open channel flow}

Mixing processes at river confluences: Field informed numerical modelling

S.N.Lane, K.F.Bradbrook, S.W.B.Caudwell \& K.S.Richards

Numerical modelling of two-dimensional turbulent air-water flows with evaporation

H.Q.Ni, L.X.Zhou \& ZJ.Zou

Generalized second moment method for advection and diffusion processes

V.H.Chu \& W.Altai

Transverse mixing of solute and suspended sediment from a river outfall during over bank

flow

K.J.Spence, I.Guymer, J.R.West \& B.Sander

Lateral turbulent dispersion in compound channels: Some experimental and field results

X.Liu, D.W.Knight, B.Jiu \& T.Gong

Numerical investigation of zero-mean flow turbulence near a free surface

Y.Sugihara \& N.Matsunaga

Improvements of depth-averaged $\kappa-\varepsilon$ turbulence model

S.Yano, T.Komatsu \& Y.Nakamura 
Vertical mixing processes due to waves and currents

J.M.Pearson \& 1.Guymer

A theoretical study on complete mixing distance in open-channel uniform flow

K.Z.Huang \& Tao Jiang

Measuring velocities in a suspension

T.Dreier, J. Bühler, W.Kinzelbach \& M.Virant

\subsection{Stratified flows}

On the 'stratification drag'

A.N.Srdić-Mitrović \& H.J.S.Fernando

Interfacial instabilities in exchange flows

D.Z.Zhu \& G.A.Lawrence

Laboratory investigation of a three dimensional wall attached density current down an inclined slope in a rotating tank

N.E.Kotsovinos \& P.Kralis

Vertical velocity profiles of turbulent two-layer flow

425

Y.Wang, A. Dittrich \& F.Nestmann

Regimes of exchange flows

D.Z.Zhu \& G.A.Lawrence

Laboratory model studies of flushing of trapped salt water from a blocked tidal estuary

P.A.Davies, Y.Guo, M.J.Coates \& J.Cremers

Simulation of steady three-dimensional boundary-attached density currents

G.M.Horsch, G.C.Christodoulou \& M.Varvayanni

Turbulent gravity current of lock release type: A numerical study

G.Q.Chen \& J.H.W.Lee

A computational fluid dynamics (CFD) investigation of stratified flows

B.Donnelly, G.A.Hamill, D.J.Robinson, P.Mackinnon \& H.T.Johnston

Application of computational fluid dynamics (CFD) to model entrainment across a density

stratified interface

Y.Oh, R.Burrows \& K.H.M.Ali

Contaminant transport in a temperature-stratified reservoir

R.Gu \& S.W.Chung

Numercial calculation on generation process and diffusion phenomenon of muddy water caused by sand dumping into water

T.Shigematsu, K.Oda \& S. Horii

\subsection{Air-water interaction}

Accuracy of tracer measurement of gas-desorption rates 
A relationship between spray quantity above white caps and wind shear stress

N.Matsunaga, M.Hashida \& K.Uzaki

Numerical modeling of wind-induced currents in shallow lake

J.Li, S.Liu, S.Li \& X.Yu

Heat balance analysis in the Bay of Tokyo

499

P.J.Baruah \& S. Kazama

\subsection{Environmental fluid mechanics}

Large eddy simulation of oscillating flows over a flat plate

C.T.Hsu \& X.Lu

Steady streaming in an oscillatory flow over a periodic wavy surface

X.Lu \& C.T.Hsu

Dispersion of vapour in a layered unsaturated zone

C.O.Ng

Shear flows in shallow water: Foundation and accuracy of the rigid-lid assumption

M.S.Ghidaoui, J.Q.Deng \& A.A.Kolyshkin

Dispersion of a small solid spherical particle in turbulent flows

D.Jiang, Z.Huang, W.Qian \& W.Wang

\section{$3 \quad$ Hydraulics and water quality}

\subsection{Water quality model studies}

Invited lecture: Modelling salt, sediment and heavy metal fluxes in estuarine waters

R.A. Falconer \& B.Lin

A post audit of nutrient reductions in two estuaries

W.S.Lung

Transmission of nitrogen and phosphorus in the Maizuru Bay and proposal of improvement method for water quality

A. Daido, H.Miwa \& H.Ikeno

Modelling the effects of macrophyte decomposition on the nutrient budget in shallow lakes

T.Asaeda, T.V.Bon, T.Fujino \& V.K.Trung

Water quality simulation in reaches of Hanjiang River by 2D model

D. H.Zhao, C.Qi \& H.W.Shen

An improved phosphorus budget model and its application to Lake Yanaka

G. Huang \& N.Tamai

Water quality model and management information system for a shallow water sea bay

J.Tao \& ZWang

La Laguna Las Peonias - A case study of an inverse estuary 
Non-dimensional steady-state model for volatile toxics in a lake

C.Gualtieri \& G.P.Doria

Field observation of heat budget on a tidal flat

N.Matsunaga, M. Kodama, Y.Sugihara \& K.Fukuda

603

Analysis of water quality variation along a regulated stream in Sri Lanka

K.D.W.Nandalal

Contaminant transport model of confined dike facilities

609

T.Kuppusamy

A method of estimating the effective hydraulic conductivity for moisture transport in

porous media

A.W.Jayawardena \& P.B.G.Dissanayake

\subsection{Cooling water studies}

The generating method of river-regime-fitted or river-mainstream-fitted orthogonal grid

and its applications

Y.H.Dong

Numerical simulation and experimental study of cooling water project and thermal pollution of HL Thermal Power Plant

W.Jiang, Y.Lin \& Z.Wang

Numerical simulation for eutrophication in lakes with cooling water circulation

K.Chen \& P.Li

\subsection{Environmental impact studies/Three Gorges Project}

Hong Kong's worst red tide

M.D.Dickman

Fisheries at Shimonoseki area and waste management

T.Kano, K.Torii \& H.Yamakawa

Impact of quarrying coarse gravel from river channel

J.Peng

Impact of the Yangtze Three Gorges Project on hydraulics and water quality

Z.Fang

The contents, methods and progresses of water pollution control of the Three Gorges

Reservoir on the Yangtze River (WPC-TGR)

Z.L.Huang, Y.C.Chen, Y.L.Li \& C.B.Jiang

Preliminary study on longitudinal dispersion coefficient for the Three Gorges Reservoir

Z.Huang, J.Li \& J.Huang

Impact of sediment movement on the water quality of Three Gorge Reservoir

J.Huang \& J.Li

Numerical simulation of flow in scour of downstream of Three Gorge spillway 


\subsection{Water quality management}

An application of the adjoint technique to locating wastewater discharges into a surface water 693 system

J.Q.Deng, M.S.Ghidaoui \& D.A.McInnis

Simulation of coastal water pollution with fuzzy parameters

H.Mpimpas, P.Anagnostopoulos \& J.Ganoulis

Study in the method of predicting the water environmental capacity in a river basin

L. Liu \& X.Zhang

\section{Sediment-water-environment interactions/Other topics}

\subsection{Sediment/Contaminant transport}

Invited lecture: Effect of sediment on pollutant transport-transformation

Z.Wan \& H. Suiliang

Invited lecture: The influence of fine sediments on water quality

N.V.M.Odd

Modeling transport and fate of contaminants with sediment interaction and transient storage in streams

Z.Yi \& M.M.Aral

Artificial flood release, a tool for studying river channel behaviour

A. Krein \& W.Symader

Turbulent effect on heavy metal release from river suspended sediments

X.D.Zhou, Y.Wang \& T.L.Huang

Desorption of cadmium from suspended particles in a turbulence tank

H. Suiliang \& O.W.H.Wai

\subsection{Modelling of collection and treatment systems}

Towards a model to understand foul flushes in combined sewers

D.Y.Kwon \& S.Vigneswaran

Flocculation with the aid of hydraulic jets

N.Suresh Kumar, S.G.Joshi \& B.S.Pani

Floating medium flocculator/filter: Is unsaturated flow regime superior to saturated flow regime?

S.Vigneswaran, R.Ben Aim, A.Shanoun, V.Jegatheesan, S.Santhikumar \& H.H.Ngo 
Hydrodynamic and sediment problems of biological contact aeration process for water supply 789 source pre-treatment B.Huang, G.Lai, J.Qiu \& Z.Li

Water mixing and exchanging in biological contact oxidation process flumes of water supply 795 works and wastewater engineering Y.Lai, G.Lai \& Z.Li

\subsection{Sediment management}

River catchment sanitation by sediment management - A Flemish case study

M.Huygens, R.Verhoeven, C.Janssens \& M.Vangheluwe

Disposal of contaminated mud in Hong Kong: A review of the environmental monitoring programme

A.L.C.Chan \& A.Dawes

Development of Hong Kong's decision criteria for sediment disposal

P.C.K.Lei, A.W.K.Fok, A.Dawes \& P.G.D.Whiteside

In situ sediment treatment in Kai Tak Nullah Approach Channel to control odours and methane gas production

J.M.Babin, T.P.Murphy \& J.T.Lynn

Managing contaminated sediment in a scenic river across a new town

D.S.W.Tang \& L.M.C.Lau

\subsection{Eco-hydraulics}

Observations on characteristics of flow and production of attached algae at riffles and pools in gravel rivers Y.Toda \& S. Ikeda

A field observation on water purification system in reservoirs using wave energy T.Komatsu, T.Okada, S.Marui, Y.Matsunaga, S.Nakashima \& K.Fujita

Basic concepts of urban disaster prevention channels into environmentally friendly channels

S. Shigeoka, K.Teshima \& M.Oono

Experimental studies on a system for catching Oncomelania in irrigation channels

H.Chen, Z.Pan \& C.He

A low flow increase for improving river environment

H. Sakata

\subsection{River hydraulics/hydrology}

A study on the numerical model of non-equilibrium sediment transport in unsteady flow S.H.Lee 
River junction design for urban flood control: A case study

J.H.W.Lee, H.W.Tang, W.C.Chan, G.Wilson

The influence of sea level rise upon flood/tidal level of the Pearl River Delta

883

Z.Li, B. Huang \& J.Qiu

Different alignments of a new hydraulic structure using 2-D mathematical model

S.A.S.Ibrahim, M.B.A.Saad \& A.A.El-Desoky

Velocity distribution at channel bifurcations

895

M.Lutfor Rahman, M.R.Kabir \& M.M.Hossain

Regulator with gravity flap gate

901

M.R.Kabir, J.J.Veldman \& A. K. M.Nazrul Islam Howlader

\subsection{Coastal hydraulics}

A soft coastal defence system for the Belgium East Coast

M.Huygens, N.Van de Voorde \& R.Verhoeven

Attenuation and phase delay of dynamic pressure propagated into reclaimed zone

behind caisson-type seawall

T.Shigemura, M.Yokonuma, K. Hayashi \& K.Fujima

A constrained dual membrane wave barrier

923

E.Y.M.Lo

Effects of coral reefs on the nearshore coastal dynamics

H. Karunarathna

Modelling wave propagation in nearshore area

B.Liu \& Z.Zidan

Study on water quality model for mild slope beach bay

Z.Wang \& Z.Huang

\subsection{Miscellaneous}

Stochastic analysis of Richards equation under uncertainty in unsaturated soil parameters

K.S. Hari Prasad, J.Q.Deng \& M.S.Ghidaoui

Characteristics of ocean currents near Hong Kong by analysis of two ADCP data sets

Y.G.Wo \& J.H.W.Lee

Experimental study on the resistance of roll-wave flow

M. Miyajima

Development of a non-contact method of measuring river depth from the air

Y.Okamoto

Effects of colloidal chemistry on fine particle deposition within a viscous porous flow Z.Wang 